\title{
Outdoor Equipment
}

It is a part of the public duty of those who know the value of our natural endowment to protect and preserve some portion of it wherever possible, and to put it to educational use. We, as a people, have had the American soil in our keeping for only a few generations; and yet we have well nigh extinguished its native life over large areas. It is well to have fields and stock-pens, for we must be fed and clothed: but, it is well, also, to have something to show of the richness and resourcefulness of nature, for we must be educated.

Coming generations will need the wild things. Without seeing them, they will never understand the history of their own country. They will never know what things confronted their forefathers to baffle them: what things gave them succor and enabled them to live here and establish a new nation. They will want to know what the native life of their native land was like.

There is plenty of wild life of many sorts in America still, but it is getting farther and farther from the haunts of men and lost to its former use. The attention of youth is occupied more and more with artificialities. The wild places near at hand are made unclean, and then are shunned. Our necessary "improvements" are made with much unnecessary waste and heedless despoiling of the beauties of nature.

This is largely due to ignorance. That anything wild is worth saving has hardly occurred to the average citizen: that anything wild may be saved without hindering improvements is an idea foreign to his experience. For he has been filled with zeal to make the world over; to cut down all the woods and drain all the bogs, and fill all the ravines with rubbish; to reduce it all to a neat pattern of cement sidewalks, encircling lawns and cabbage patches. 
In the cities where the pressure for room has been greatest and the destruction of native wild life completest, men have cried out for nature and for green things growing, and parks have been made. But the average park is a stretch of grass to be kept off from, and the best of parks are good and wholesome and inspiring and informing in proportion as they reproduce the wildwood.

So before the last bits of wildwood near us have been destroyed, it is time to think of preserving some of them for the sake of those who shall come after us. This was not necessary in the days of the pioneer, but with rising land values and more intensive agriculture, the extermination of the wild life is proceeding at an ever accelerating rate. The rich life of the Illinois prairies is a memory. The streams in all our settled parts have been made barren and unclean. The swamps-nature's own sanctuaries-are bcing drained. In the better agricuitural arcas of America, we have almost reached that day of desolation when the possession of a natural grove, or of a wild-flower preserve, however small, is enough to give a farm distinction-to mark it as a home of culture.

Three things a naturalist should do for the public good. He should endeavor: (1) to prevent unnecessary and illconsidered destruction of natural beauty everywhere: (2) to aid nature in the restoration of beauty to waste places: (3) to make the bits of nature near at hand more serviceable in the education of the public.

Saving the remnant. It will not do for those who best know the esthetic and educational values of wild life to merely sit back lamenting when its extinction is threatened. When natural beauty spots are about to be ravaged and stocked with artificial gewgaws; when the public roadsides are to be shorn of their copses of flowering shrubbery, only to be made into weed patches; when flower decked 
ravines are to be turned into rat-hatcheries by filling them with garbage and rubbish; when sparkling streams are to be fouled with stinking slops and oils by the slovenliness of some streamside factory; when public groves are to be cleared without any intelligent supervision, merely to provide work for a public labor-gang in the slack season:- whenever these or any other such things, as are occuring daily all over the land, are about to be committed, it is the duty of the naturalist to speak out in protest. He should endeavor to enlist the enlightened public sentiment of his community, to have the esthetic and educational values of such places considered, ere they are destroyed. They are sure to be undervalued because they have cost the public nothing. In this they are like all true gifts of heaven.

In city communities, there are Audubon societies, and wildflower preservation societies, and civic improvement societies, and conservation societies, etc., that include in their membership the best brains and culture of the place; and the aid of such organizations is easily enlisted in such a cause. In any community there are those that love the beauty and freshness of unspoiled nature, and who will gladly use their influence toward saving something for future enjoyment. The first thing to be done is to see that those administering the public works in question are informed of the value of the wild things about to be destroyed. Often, it is necessary that they be informed of the very existence of such things. Next there is need of eternal vigilance.

Improving waste places. When necessary public works, however destructive of natural scenery, have been completed, then a little careful forethought for the use of the things nature freely offers, will make the place beautiful again. The naturalist should assist in planning their betterment. He of all people, should know what things are most available, and best suited to every use and situation. 
Suppose a bridge is to be built. Everybody knows that an old bridge, settled in the midst of clumps of greenery and spanning a clear stream makes a beautiful picture. A new bridge looks otherwise: it rises starkly from a sea of mud, joins two new-born dump heaps. For, when a bridge is built, usually just enough money is appropriated to do the necessary excavating, to dispose of the dirt in the easiest way and to put up the bridge itself: nothing is available for restoring beauty to the place. What are the things needed for this? Willows by the waterside: filmy pale green small-leaved wild willows, to nestle in soft masses by the abutments: elms and sycamores to cover the rising slopes; or vines, if the dump be of broken stone: swamp iris or water shamrock to cover the bare mud-things that do not cost a cent for they may be found in nature's wild nurseries; things that will grow without any coddling, that need only proper planting-in short the things that grow wild in such places. These will restore the beauty of the place in the minimum of time, and with the least expense. In the course of years, nature, if not prevented, will restore these things herself: but the effect will be better, and the desired results will be attained much more quickly for a little intelligent aid.

So, roadsides, that are considered "finished" when a roadbed is secured, may be refurnished: level filled lands may be made fresh green meadows, instead of being allowed to become wildernesses of weeds: slopes disfigured with stumpage may be reforested. It should be the privilege of the naturalist to enlist public spirited folk in the promotion of such betterments. It will help the good name of his community.

The greater the number of people who can be got to participate in this work, the better it will be established in public opinion: the more children helping, the better its results will be insured against future vandalism. About schools and colleges, things should be planted, not solely 
for ornament, as at present, but for their educational usefulness as well.

Making natural reserves servicable. Education began in "fresh air schools". Country folk have always been wont to meet in groves for public exercises. The fresh air and the open sky, the majesty of the trees, and the freshness of the unspoiled verdure have irresistibly drawn them out of doors. With the revival of interest in field work, we are going out doors in companies again and taking some of our work with us.

It is not so easy now, as once it was, to find a spot prepared by nature for a gathering place. The requisite conditions are that all who come together shall be able to see and to hear and to sit comfortably while listening or working. A grassy bank under a tree, when dry enough, may meet these conditions. For many years a few great trunks of fallen trees in the Renwick woods at Ithaca served as meeting places for classes in biological field work. But places better suited to the needs of classes may easily be arranged in the woods.

For more continuous use as an outdoor class room, "The Covert," at Ithaca was made. A natural hollow in the woods, over-arched and shaded by trees, was fitted with seats of flat field-stones, arranged in semi-circles. Aisles were left for passing and paths were made for entrance and exit. At the center a massive table, with a slate slab for a top, was built of hollow tile and plastered. A door was set in the back of its hollow base, and its interior is used for the storage of grass mats, between sessions. These mats are handed out for use by classes when the stones are damp and cold. "The Covert" is an excellent type of educational equipment that can be made in any woods. It is very substantial and permanent. It does not disfigure the woods (being hardly discernible from a distance of a few rods in any direction) and it is growing in beauty every year as its trees grow older, 
its paths become better turfed, and its surrounding plantings develop. It was made by a few weeks of labor on the part of two students, and it cost less than ten dollars for materials.

Gathering places for larger numbers may be made on the same general plan. The author once took a class in natural history out to a small grove, and set the members studying the trees and the slopes with a view to locating and arranging therein, with the least possible disturbance to the wild wood, an outdoor auditorium for public addresses, concerts and sylvan plays. The result is the simply arranged natural amphitheater shown in fig. I40: $A$ is the floor plan; $B$ is

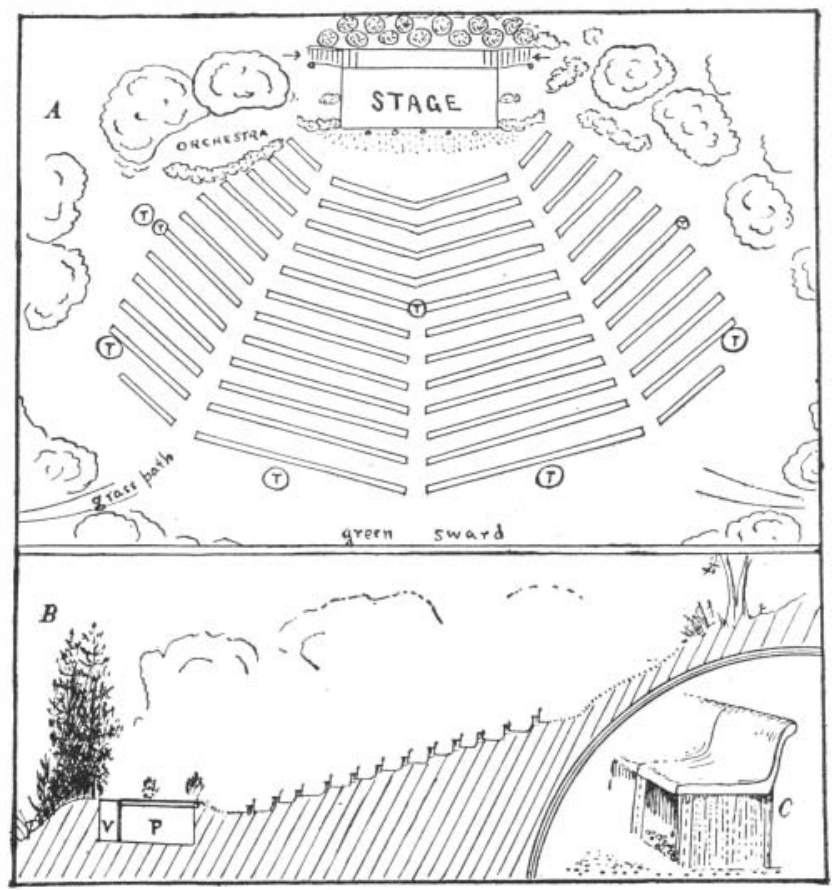

FIG. 140. Diagram of an outdoor auditorium. 
a vertical section, showing a properties-room, $P$ beneath the stage, and a vestibule, $V$, for entrance from the rear; and $C$ is the end of a row of seats. In the floor plan $T, T, T$, etc., indicate the trunks of high-crowned trees, left standing to furnish shade. The artificialities of the plan are such only as are necessary: comfortable seats, conveniently arranged, and a good stage. These are made of cement on ribbed metal lath, plastered on both sides and colored green or gray or brown. The sylvan picture round about is carefully preserved. The aisles are grass paths. Under the seats are beds of violets. Greensward masks the stage and low evergreens define front and rear stage entrances. A bank of tall evergreens furnishes a background at the rear of the stage. All around are trees for shade. A rising turf covered bank at the rear of the seats provides for overflow on great occasions, the limit of capacity being set by a bank of evergreens fronted with thorny barberry. Vines added for grace, and flowering trees and shrubs for color are used to fill surrounding niches. Thick walls of verdure round about exclude outside distractions. Grass paths of ample width, well defined by border plantings, give easy access, and invite pedestrians to keep off the other vegetation.

No community will long gather in such places without coming to feel an interest in the wild things. By the possession and use of such outdoor places, the public may be educated in the appreciation of nature. 